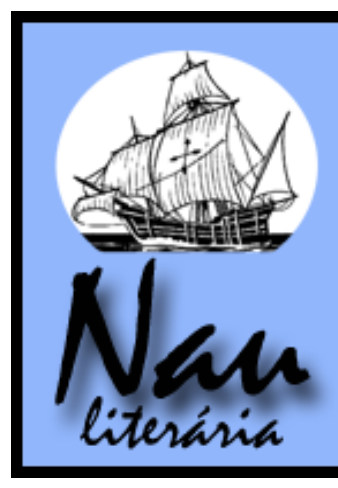

\title{
Relações entre memória, reterritorialização e identidade cultural em Duas iguais, de Cíntia Moscovich
}

\section{Manuela Matté* Salete Rosa Pezzi dos Santos ${ }^{* *}$}

\begin{abstract}
Resumo: Este artigo discute as relações entre memória e territorialidade na constituição da identidade cultural judaica no romance contemporâneo Duas iguais (2004), de Cíntia Moscovich. O fio que conduz essa discussão é a questão regional, visto que o contexto de inserção da narrativa é uma comunidade regional judaica, em Porto Alegre. Discute-se, assim, como a memória coletiva contribui para a manutenção da identidade nacional judaica, bem como a reterritorialização permite a formação de novas identidades regionais judaicas.
\end{abstract}

Palavras-chave: Nação; Comunidade Regional; Jewish Culture

\begin{abstract}
This paper discusses the relations between memory and territoriality in the Jewish cultural identity constitution in the contemporary novel Duas iguais (2004), by Cíntia Moscovich. The thread which conduces this discussion is the regional issue, once the narrative's insertion context is a Jewish regional community, in Porto Alegre. It is discusses, therefore, how the memory contributes to the national Jewish identity maintenance, and also how the reterritorialization provides the formation of new regional Jewish identities.
\end{abstract}

Key-words: Nation; Regional Community; Identity; Identidade; Cultura Judaica.

A identidade é uma construção social e simbólica e, atualmente, longe da concepção cartesiana, é considerada de forma múltipla e plural. Enquanto indivíduos, somos dotados não de uma única, fixa e estável identidade a priori, mas de múltiplas possibilidades de identificação pessoal e cultural. Dentre as várias possibilidades de identidades culturais que podemos assumir está a identidade nacional, considerada fonte fundamental de identidade cultural (HALL, 2005).

A identidade nacional, de acordo com Hall (2005), faz parte de um sistema de representação cultural. A nação é o que Benedict Anderson (2008) chamou de "comunidade imaginada": "ela é imaginada porque mesmo os membros da mais minúscula das nações jamais conhecerão, encontrarão, ou sequer ouvirão falar da maioria de seus companheiros, embora todos tenham em mente a imagem viva da comunhão entre eles" (ANDERSON, 2008, p. 32). Alguns elementos são fundamentais para garantir que todos que compartilham da

\footnotetext{
${ }^{*}$ Mestre em Letras, Cultura e Regionalidade, pela Universidade de Caxias do Sul (UCS). Professora de Língua Portuguesa e Literatura da Rede Pública de Ensino.

${ }^{* *}$ Doutora em Letras-Literatura Comparada, pela UFRGS. Professora e pesquisadora no Curso de Letras e no programa de Pós-graduação stricto sensu da Universidade de Caxias do Sul (UCS).
} 
mesma identidade nacional possuam essa imagem viva da nação, de que fala Anderson (2008). O discurso da cultura nacional é composto, entre outros elementos, pelas narrativas nacionais (que incluem literatura e cultura popular); pela ênfase nas origens, na continuidade, na tradição e na intemporalidade da nação; pela invenção das tradições; pela existência de um mito de fundação e pela crença na originalidade do povo (HALL, 2005). Mesmo compostas por membros que, além de não se conhecerem, diferem quanto à raça, à religião, à classe social, as identidades nacionais procuram neutralizar as diferenças para que todos se sintam cidadãos de uma mesma nação (HALL, 2005).

Os judeus constituem um caso interessante de identidade cultural nacional, "um caso único no tocante à preservação de formas culturais em contextos de dispersão territorial" (MENTLIK, 2005, p. 66). Em diferentes períodos da história, durante, aproximadamente, dois mil anos, em função de diversas expulsões e diásporas, a comunidade judaica teve de abandonar seus países de procedência e emigrar para outros países. Esse fato contribuiu para que houvesse uma diversidade ímpar entre os que se consideram judeus, diversidade que se intensificou, principalmente, a partir de seu estabelecimento em novos países, em novas regiões. Ao mesmo tempo, porém, a maioria dos pertencentes à comunidade judaica continuou reiterando sua "judeidade", reivindicando, inclusive, um espaço nacional em comum, o estado de Israel:

havendo se estabelecido em diversos territórios durante sua longa dispersão que remonta a 70 d.C. (data da destruição do II Templo), organizando-se em pequenas comunidades nas mais variadas regiões do planeta, possivelmente com pouca intercomunicação durante largos períodos, esse povo logrou manter intacta alguma forma de identidade religiosa e cultural com vitalidade suficiente para reunificá-lo no Estado de Israel desde 1948, bem como para preservar, até os dias de hoje, várias coletividades judaicas na Diáspora (MENTLIK, 2005, p. 66).

Mesmo reterritorializados, os judeus tendem a manter uma imagem e memória viva de suas origens, das perseguições sofridas, das tragédias e dizimações enfrentadas. Procuram ressignificar grande parte das tradições e costumes e continuam perpetuando-os através das gerações: no Brasil, embora muitos tenham chegado "numa situação extrema, ameaçados de aniquilamento, [...] não se desfizeram dos padrões e hábitos que mantinham antes da imigração" (MENTLIK, 2005, p. 72). A memória coletiva, nesse sentido, teve e tem poder fundamental para garantir essa manutenção da identidade judaica, reformulada em novas identidades judaicas regionais.

O presente artigo, assim, pretende analisar como a memória coletiva, diante da (re)territorialidade judaica, contribuiu e continua contribuindo para a (re)construção e manutenção da identidade cultural nacional judaica em diferentes territórios. Como objeto 
deste estudo, analisa-se a obra literária contemporânea Duas iguais (2004), de Cíntia Moscovich, escritora judia, cuja obra pode ser considerada de memória vicária, uma vez que se trata de um texto produzido no período pós-Shoah. Segundo Waldman (2009), a memória do Holocausto tem se consolidado, cada vez mais, na ficção, através de escritores, poetas, historiadores, filósofos, já que são raras as testemunhas diretas ainda vivas. (WALDMAN, 2009).

Cíntia Moscovich tem se destacado nas letras nacionais, fato atestado pelos inúmeros prêmios recebidos, importantes para a literatura sul-rio-grandense, como o primeiro lugar conquistado no Concurso de Contos Guimarães Rosa, instituído pelo Departamento de Línguas Ibéricas da Radio France Internationale. Sua obra Duas iguais, cuja primeira edição data de 1998, foi vencedora do prêmio Açorianos de Literatura. Em 2013, recebeu o Prêmio Portugal Telecom de Literatura em Língua Portuguesa, na categoria contos, com a obra Essa coisa brilhante que é a chuva (2012). A temática judaica é recorrente na produção de Cíntia e, geralmente, serve de contexto para os conflitos vivenciados por suas personagens, na maioria das vezes, mulheres.

Em Duais iguais, encontram-se representadas, a partir da memória individual e coletiva da personagem feminina Clara, a construção e a manutenção da identidade cultural judaica em uma comunidade regional gaúcha. O romance apresenta o conflito de subjetividade e identidade de Clara, uma jovem judia pertencente a uma comunidade regional judaica de Porto Alegre - o bairro Bom Fim ${ }^{1}$-, nas décadas da ditadura militar brasileira. $\mathrm{O}$ romance - narrado em primeira pessoa por Clara, que, no momento da narração, possui aproximadamente quarenta anos - conta a relação homoerótica entre duas adolescentes durante os anos 1970. Clara apaixona-se por sua melhor amiga, Ana, mas decide afastar-se dela em função do preconceito social por parte dos colegas da escola e em função da não aprovação de sua família, principalmente, de seu pai. Para Clara, ele sempre fora uma referência fundamental e, quando da sua morte, a adolescente sente-se desestruturada e insegura, especialmente nos momentos que exigem dela tomada de decisões. Mesmo com a ausência da figura paterna, Clara continua seguindo os ensinamentos do pai como referência em sua vida. Casa-se, seguindo o incentivo da família, com um judeu, neto de rabino,

\footnotetext{
${ }^{1}$ De acordo com Mentlik (2005, p. 68), no século XX, os judeus que chegavam ao Brasil eram majoritariamente provenientes da Bessarábia (Rússia) e fundaram as colônias agrícolas de Philippson e Quatro Irmãos, localidades próximas à Santa Maria, no Rio Grande do Sul. Segundo Santos e Soares (2012), os judeus, inicialmente estabelecidos no interior do estado do Rio Grande do Sul, começaram a estabelecer-se em Porto Alegre, lugar visto como favorável para a formação de uma comunidade judaica. O bairro Bom Fim, atualmente, permanece como representante da cultura judaica em Porto Alegre. Segundo Dias (2012), Porto Alegre abriga a segunda maior comunidade judaica do Brasil, com uma população aproximada de 10.000 judeus.
} 
vivendo, por muitos anos, uma vida em que não se sentia protagonista das suas próprias escolhas. No entanto, assume sua subjetividade, seus sentimentos e emoções, no momento em que está diante da possível perda da pessoa amada. Clara decide assumir o seu amor, separarse do marido e reencontrar Ana, anos depois, quando essa volta ao Brasil, às vésperas de uma cirurgia gravíssima em função de uma má formação cerebral. Ana falece durante a operação, e Clara, nos anos que seguem, passa a narrar para si mesma o acontecido. Segundo Sarlo (2007, p.19), a pessoa narra a sua vida "para conservar a lembrança ou para reparar uma identidade machucada". A narração das memórias, assim, contribui para a constituição de Clara enquanto sujeito e permite que assuma, para si mesma, sua identidade.

A noção de que memória e identidade estão intrinsecamente relacionadas é recente. De acordo com Lowenthal (1998), a ideia de que o passado faz parte da identidade só surgiu com a modernidade, quando se começou a enxergar o presente em constante diálogo com o passado. Conforme Anderson (2008), a identidade é impossível de ser totalmente rememorada, por isso, a narrativa da identidade, ou, a autoapresentação através de narrativas, é fundamental na percepção identitária do sujeito. Entende-se identidade, aqui, como a "imagem que uma pessoa adquire ao longo da vida referente a ela própria, a imagem que ela constrói e apresenta aos outros e a si própria, para acreditar na sua própria representação, mas também para ser percebida da maneira como quer ser percebida pelos outros." (POLLAK, 1992, p. 5). Segundo Candau (2012), a memória pode tanto consolidar quanto destruir a identidade e, sem memória, o sujeito desaparece e é incapaz de captar e compreender o mundo. Dessa forma, a narração de suas memórias contribui para a própria narração da sua identidade pessoal e da identidade coletiva do grupo com o qual se identifica:

é no mesmo movimento dialético que a memória vem confortar ou enfraquecer as representações identitárias, e estas vêm reforçar ou enfraquecer a memória. Em todos os casos, esse trabalho de memória é coletivo desde sua origem, pois se manifesta "no tecido das imagens e da linguagem" que devemos à sociedade e que nos vai permitir dar uma ordem ao mundo. (CANDAU, 2012, p. 78).

Ao contar sua história, de forma autobiográfica, a narradora procura dominar e organizar seu passado, o que equivale a dominar e organizar sua identidade enquanto sujeito. Clara inicia a narrativa, deixando claro, "preto no branco" (MOSCOVICH, 2004, p. 11), que está contanto a história de sua vida, logo, contando - ou tentando contar - quem ela é. Conforme Candau (2012, p. 71),

o narrador parece colocar em ordem e tornar coerentes os acontecimentos de sua vida que julga significativos no momento mesmo da narrativa: restituições, ajustes, invenções, modificações, simplificações, "sublimações", esquematizações, esquecimentos, censuras, resistências, não ditos, recusas, "vida sonhada", ancoragens, interpretações e reinterpretações constituem a trama 
desse ato de memória que é sempre uma excelente ilustração das estratégias identitárias que operam em toda narrativa.

A partir das memórias da personagem Clara, não só sua identidade pessoal se constitui como também é possível perceber muitos elementos da identidade cultural do seu grupo de pertença e identificação, a comunidade judaica do Bom Fim. O espaço cultural de inserção de um indivíduo, lugar de interação com outros indivíduos e a sociedade como um todo, traz importantes contribuições à construção da identidade. Desde tenra idade, o indivíduo constrói-se e é construído a partir das experiências que vive, as quais estão em constante diálogo com o seu entorno e as pessoas que o compõem.

Enquanto ser que se relaciona com esse contexto e nele interage, na comunidade regional em que está inserido, o sujeito desenvolve suas identidades, afirmando-as e expressando-as, ou não. Comunidade regional pode ser tomada como sinônimo de região cultural, um espaço composto por especificidades que o distinguem de outros espaços: "uma região cultural é composta por especificidades (assim, no plural) materiais e imateriais regionalidades que armam um tecido complexo e flexível, o qual se mostra sempre outro a cada novo olhar." (ARENDT, 2012, p. 89). As regionalidades, por sua vez, "não constituem conjuntos de objetos passíveis de serem pensados fora de seus contextos particulares de significação" (SANTOS, 2009, p. 16). Conforme Santos (2009, p. 3), "o regional coloca-se como um elemento significativo da representação da identidade".

Para abordar a ideia de regional, ou de região, porém, faz-se necessário, primeiro, analisar a noção de espaço. Embora essa noção tenha sido, ao longo das décadas, desprivilegiada em relação à noção de tempo/história (MASSEY, 2008), faz-se fundamental observar o espaço de inserção cultural da personagem para que se percebam as relações nele estabelecidas. Conforme Massey (2008, p. 56), "a vida é tanto espacial quanto temporal", não há como estabelecer hegemonia de uma dimensão sobre outra, até porque ambas estão em permanente devir (MASSEY, 2008). Dessa forma, acredita-se que a noção de espaço, entendido não apenas como uma categoria geográfica a priori, mas como uma realidade que resulta das interações e das experiências humanas, seja tão importante quanto a noção de tempo (história) na análise do contexto da obra literária. Conforme propõe Massey (2008, p. 29), "primeiro, reconhecemos o espaço como produto de inter-relações, como sendo constituído através de interações, [...]. Segundo, compreendemos o espaço como a esfera da possibilidade da existência da multiplicidade, [...]. Terceiro, reconhecemos o espaço como estando sempre em construção". Uma vez que o espaço geográfico, sobretudo, cultural, em que a personagem de Duas iguais se encontra é uma comunidade judaica da capital gaúcha, 
acredita-se que a melhor maneira de analisá-lo seja tomando-o a partir da perspectiva da região ou da comunidade regional.

Historicamente, os judeus foram vistos como "os outros", o que, consequentemente, contribuiu para que, em contínuos processos de diáspora, formassem grupos isolados, em diferentes partes do mundo. Conforme Oliveira (2006), a terra ou território é o primeiro operador simbólico na definição da identidade. Os possuidores da terra constituem o "nós", enquanto que os destituídos de terra constituem "os outros". Em função das diásporas, os judeus têm sido considerados os outros, principalmente, por estabelecerem-se em terras que não são suas.

Conforme Sennet (2008), o processo de isolamento dos judeus iniciou-se a partir do Renascimento e ganhou força na modernidade, resultando na formação de guetos. No Brasil, país que conta atualmente com uma população de, aproximadamente, 95.300 judeus $^{2}$, a recepção à imigração judaica nos séculos XIX e XX foi, por um lado, vista com bons olhos pelo governo, por se tratar de mão de obra imigrante, profícua, portanto, ao desenvolvimento previsto para o país. Por outro lado, a imigração judaica no século XX foi, em grande parte, tomada de preconceitos antissemitas, inclusive por parte do governo brasileiro (CARNEIRO, 2007). A política nacionalista, com a proibição do uso de línguas estrangeiras na Era Vargas, é um exemplo das dificuldades enfrentadas pelos imigrantes judeus que chegavam ao país, à época. (GUTFREIND, 2004; MENTLIK, 2005). De acordo com Freyre (2001), quando da chegada dos imigrantes ao Brasil, no final do século XIX, frades iam aos portos não para verificar a nacionalidade dos que chegavam, mas sua religião: "se fosse judeu, teria que se disfarçar em cristão-novo embora secretamente continuasse judeu" (FREYRE, 2001, p. 6869). No Rio Grande do Sul, a história da imigração judaica sempre ficou em segundo plano, pois o empenho dos intelectuais sul-rio-grandenses estava voltado à afirmação do discurso de brasilidade do gaúcho (GUTFREIND, 2004).

Ao se estabelecerem nesses novos espaços geográficos, num processo de migração e reterritorialização, os judeus passaram a viver com suas famílias, em grupos, os shtetlech, ou pequenas aldeias (SELTZER, 1990). De acordo com Santos e Soares (2012), o que leva os grupos à imigração, geralmente, é o aspecto econômico; porém, no caso judaico, as discriminações e perseguições foram o principal motivo da necessidade de reterritorialização. Partindo de seus diferentes países de origem e chegando a lugares completamente novos, onde

\footnotetext{
2 Fonte: "The jewish population in the world". Disponível em: <http://www.jewishvirtuallibrary.org/jsource/Judaism/jewpop.html>. Acesso em: 28 jan. 2014. Na época em que se passa o enredo de Duas iguais, durante a década de 1970, havia cerca de 160.000 judeus no Brasil (SELTZER, 1990).
} 
tiveram de moldar-se à nova cultura, desenvolveram uma nova identidade cultural, a partir de regionalidades (ou particularidades), e atribuíram essa identidade a esses novos espaços, ou regiões culturais, que não eram mais idênticos aos seus lugares de partida (suas nações), mas que possuíam muito da sua marca de "judeidade", principalmente, através da conservação da língua do país de origem, da gastronomia e da religião (DIAS, 2012). No caso específico do Brasil, a identidade judaica foi bastante preservada, mesmo diante das particularidades dos muitos grupos de judeus que, em diferentes períodos, se destinaram a diferentes regiões brasileiras:

a comunidade judaica brasileira, aparentemente homogênea, constitui-se, na verdade, numa colcha de retalhos, representativa da experiência do judeu no cultivo de culturas híbridas em muitos povos e culturas do planeta ao longo de sua dispersão, enfim, é um mosaico multicolorido e multiforme de identidades culturais em permanente transformação. Se a própria constituição de novas comunidades denuncia as migrações e, muitas vezes, as perseguições sofridas, ela também evidencia a capacidade de sobrevivência dessa cultura. Sua expressão mais visível reside nos laços de solidariedade interna que foram se criando, entre outras coisas, para preservar a identidade e as tradições religiosas do grupo, fazendo frente a um meio cultural hegemônico, diversificado e dinâmico. (MENTLIK, 2005, p. 73).

Embora a herança cultural judaica tenha sobrevivido, ao longo do processo histórico, através da preservação de práticas, hábitos e comportamentos individuais e grupais (MENTLIK, 2005), os elementos culturais judaicos não permaneceram intactos e idênticos aos costumes outrora praticados em seus países de origem. De acordo com Seltzer (1990, p. 622), no século XIX e XX, "atribuições e ocupações tipicamente judaicas e instituições comunitárias se desintegraram e outras novas apareceram". Os judeus procuraram manter e preservar o judaísmo, mas as transformações da modernidade "não deixaram intocado nenhum aspecto da existência humana" (SELTZER, 1990, p. 622), acarretando mudanças em todas as culturas e identidades, dentre elas, a judaica.

Dessa forma, os elementos da cultura judaica foram constituindo-se e ressignificandose em novas concepções identitárias, a partir de novas particularidades, encaradas, nesta análise, como regionalidades:

regionalidades também podem ser tomadas como índices das fronteiras culturais que se movem no tempo e no espaço. Enquanto especificidades, elas levam os indivíduos a aceitar ou a rejeitar os valores vigentes em uma escala regional. Em outros termos, ao habitar uma região, é possível identificar-se positivamente com algumas regionalidades e, ao mesmo tempo, entrar em conflito com outras. Regionalidades implicam atitudes de resistência ou de participação, de hostilidade ou de aliança, de rejeição ou de aceitação, atuando ora como obstáculos e limites, ora como continuidades e elos de ligação. (ARENDT, 2012, p. 96).

Compartilhando da mesma identidade cultural judaica, os judeus imigrantes e seus descendentes formaram, em diversos lugares do mundo, novas regiões culturais judaicas, 
como é o caso da comunidade em que se ambienta o enredo de Duas iguais. Nesses novos países em que se reterritorializaram, constituíram culturas híbridas - resultantes de múltiplos contatos que adicionaram novos elementos à nova cultura ou apenas reforçaram os antigos elementos da cultura de origem (BURKE, 2003). Agora, pertenciam a um novo país, mas não deixaram de ressignificar seus países de origem no novo local: "estas identidades constituídas foram redefinidas como identidades regionais." (THIESSE, 2001/2002, p. 18). A religião teve - e tem - papel fundamental nesse sentido, tanto na formação das nações, quanto na garantia da perpetuidade da tradição nacional: assim como uma nação reivindica soberania, também as religiões são imaginadas "principalmente pelo uso de uma língua e uma escrita sagradas" (ANDERSON, 2008, p. 40). No caso específico judaico, alia-se a noção de religião à ideia de um Estado judeu, ambas reivindicadas nos novos territórios. O discurso nacionalista da exclusividade e soberania está, em grande parte, fundamentado no discurso religioso competitivo de ser o melhor (ANDERSON, 2008). A região, por sua vez, assume o mesmo objetivo: "de criar um espaço - simbólico, bem entendido - com base no critério da exclusão, ou pelo menos da exclusividade" (POZENATO, 2003, p. 155).

Percebe-se, dessa forma, que a cultura e a religião judaicas ressignificaram suas nacionalidades em regionalidades, procurando manter as tradições nacionais nesses novos espaços, através da culinária, dos costumes, da preservação do passado comum a todos os membros dessa comunidade. A representação da região, assim como da nação, "tem também por particularidade o fato de estar baseada em uma denegação da transformação, exaltando o arcaísmo e o imobilismo de uma comunidade a-temporal que existe desde tempos imemoriais." (THIESSE, 2001/2002, p. 19). É por esse motivo que as comunidades regionais judaicas, mesmo em um novo contexto de inserção, distantes, geograficamente, dos contextos originais, mantêm muitas particularidades semelhantes às encontráveis nas nações de origem, além de outras, totalmente novas e ressignificadas por esses contextos. De acordo com Gutfreind (2004), a imigração judaica é especial porque os imigrantes originam-se de diversos países e não apenas de um, como no caso da imigração italiana ou alemã. Em função disso, se vistos de fora, são vistos como uma comunidade imigrante homogênea; entretanto, se vistos de dentro, as heterogeneidades permanecem até mesmo na definição do que é ser judeu. Ao estabelecerem-se nas comunidades regionais, os judeus criaram instituições como escolas e sinagogas a fim de permitir o agrupamento e maior homogeneização dos imigrantes.

Além dessas instituições, a memória coletiva das tragédias, segundo Candau (2012), é fundamental na constituição das identidades culturais, pois "deixa traços compartilhados por muito tempo por aqueles que sofreram ou cujos parentes ou amigos tenham sofrido, 
modificando profundamente suas personalidades" (CANDAU, 2012, p. 151). Mesmo que gerações atuais de judeus não tenham vivido as diásporas, "se comportam como se suas identidades estivessem em jogo através das lembranças dos infortúnios de seus ancestrais" (CANDAU, 2012, p. 154). Logo, a memória religiosa judaica contribui para essa manutenção de características nesses novos contextos, que se formaram a partir das diásporas judaicas:

a modalidade da memória da catástrofe tem uma longa tradição no judaísmo - uma cultura marcada pelo pacto de memória entre Deus e seu povo: um não deverá esquecer-se do outro. A religião judaica é antes de mais nada estruturada no culto da memória. Suas principais festas são rituais de rememoração da história (no Pessach, a leitura da Haggadah traz a história do êxodo com o intuito de transportar as gerações posteriores àquele evento; no Purim, recorda-se a salvação dos judeus da perseguição de Haman; no casamento judaico, em um ato de luto, um copo é quebrado para recordar, em meio à comemoração, a destruição do Templo e a impossibilidade de reparo - o tikkun na tradição da mística judaica - dessa perda). (SELIGMANN-SILVA, 2003, p. 53-54).

O Holocausto, na Segunda Guerra Mundial, tem espaço de destaque na memória coletiva dos judeus. Auschwitz faz parte da memória coletiva judaica que permanece como uma referência aos judeus até hoje (CANDAU, 2012). De acordo com Pollak (1992), a memória coletiva herdada tem uma relação intrínseca com o sentimento de identidade. $\mathrm{O}$ Holocausto, ou, em hebraico, Shoah, constitui-se como memória herdada e fundamental para as comunidades judaicas pelo mundo:

a memória do Holocausto tem ocupado também, nos últimos dez anos, um lugar central nas estratégias de comunidades judaicas para buscar mecanismos de identificação para seus membros. [...] Esta identidade judaica via reiteração da memória do Holocausto é dada sempre pelo registro da memória. (CYTRYNOWICZ, 2003, p. 132).

No caso judaico, "justamente porque a memória da tragédia é forte [...], um filho nascido de pais judeus não pode ser outro senão judeu, pelo menos durante muito tempo ainda. É a força da memória das tragédias: está sempre pronta a assombrar os indivíduos e os grupos que se consideram seus guardiões" (CANDAU, 2012, p. 156). Clara, ao ficar sabendo dos episódios de tortura que estavam acontecendo, em função da ditadura, relembra a tortura pela qual passaram seus antepassados, durante o Holocausto: "tortura era aquilo pelo qual nossas famílias haviam passado. Coisa de guerra" (MOSCOVICH, 2004, p. 27). O sentimento de identidade, baseado na diferença, é expresso por Clara através de uma comparação. A narradora compara o sofrimento vivenciado por seus antepassados a uma cicatriz cuja marca pode ser sentida, ainda hoje, nos descendentes dos judeus que foram perseguidos:

não que fôssemos grande coisa: o que nos fazia diferentes do resto da humanidade era a constante lembrança de quem havíamos sido. Alguns dos nossos pais tinham marcas visíveis do tempo da guerra. Contudo, o que nos movia era uma espécie de imensa cicatriz na alma, marcada nas lembranças, martelando, alertando que viver era perigoso. Para nós, tão tenros de existência, a vida prática era muitíssimo fácil. Por isso, por vivermos tempos de paz e de 
prosperidade, era difícil entender o que havia acontecido antes de nós. Tudo estava pronto e era bom. Tínhamos famílias, carros, casas, escolas e a promessa de um lindo futuro. Não havia sinal externo de que a vida era perigosa, só o testemunho encharcado de dor e carregado de sotaque dos parentes mais velhos. (MOSCOVICH, 2004, p. 23).

No entanto, mesmo com uma memória trágica coletiva em comum, é impossível afirmar que a experiência da "judeidade" seja a mesma em todas as comunidades regionais judaicas, pois, conforme Green (1995, p. 257), "a vida cotidiana é sempre reinterpretada em cada período e em cada lugar em que os Judeus vivem". No bairro Bom Fim, um espaço urbano, inserido na metrópole de Porto Alegre, a vida cotidiana judaica ${ }^{3}$ assumiu proporções que o tornaram uma região cultural diferenciada dentro da capital gaúcha. Segundo Arendt (2011, p. 219), a região é um "espaço histórica e culturalmente construído por diferentes formas de representação". Essas formas de representação, legitimadas a partir dos indivíduos presentes no grupo, compõem, juntas, uma região sociocultural, que pode ser reconhecida

a partir do conjunto de valores compartilhados pelos habitantes de um mesmo território; pelas formas de vida cotidiana que identificam uma comunidade e a distinguem das demais; pela existência de um passado histórico comum; e, enfim, por tudo aquilo que dá conta da existência de uma identidade cultural e que se traduz em atitudes, tradições, costumes, símbolos e crenças que são comuns a um grupo humano. (BERUMEN, 2005, p. 56).

No caso judaico, assim que se estabeleceram em Porto Alegre, os valores compartilhados pela comunidade regional judaica precisavam ser mantidos e transmitidos às gerações seguintes. Além da transmissão pela hereditariedade, a educação tem papel fundamental na cultura e na religião judaica. Com o estabelecimento dos judeus no bairro Bom Fim, foram construídas escolas israelitas, sinagogas, bibliotecas e instituições filantrópicas a fim de fazer perdurar o judaísmo no novo espaço cultural: "uma forma de marcar a identidade judaica se dá através da educação dos seus membros. A criação de escolas israelitas reafirma a identidade judaica." (DIAS, 2012, p. 44).

É na escola israelita que Clara aprende, desde cedo, que faz parte de um grupo diferente dos demais, ensinamento que procura reforçar sua identidade judaica:

os nossos nomes, na hora da chamada, pareciam uma sucessão interminável de consoantes, o que acabava por fazer com que o professor tropeçasse na própria língua, exigindo exasperadas reparações para o bem do repouso eterno de nossos ancestrais. Não, ela não era uma das nossas, o nome não conferia, não estava em nossos arquivos de memória coletiva. Se não era um dos nossos, o que fazia ali? A colega do meu lado, espanto na cara, me veio com esta:

- Será que ela vai assistir às aulas de Cultura Judaica? (MOSCOVICH, 2004, p. 24).

Ressalta-se que os nomes, na narrativa, funcionam como marcador de diferença entre identidades no binarismo judeu/não-judeu. A partir da leitura da chamada pelo professor

\footnotetext{
${ }^{3}$ Para informações sobre a cultura judaica no Rio Grande do Sul, vide "Instituto Cultural Judaico Marc Chagall": $<$ http://www.chagall.org.br/>.
} 
distinguiam-se os pertencentes àquela comunidade regional, àquela identidade, e os não pertencentes. Candau (2012), sobre a questão identitária, lembra que nomeação e memória estabelecem vínculos fundamentais no processo de afirmação de identidade.

A chegada de Ana à escola israelita é motivo de desconfiança por parte dos colegas e suas famílias, majoritariamente judeus. Os colegas da escola enxergam-na como alguém que não é "dos nossos" (MOSCOVICH, 2004, p. 25), o que comprova o compartilhamento e a busca por legitimação das mesmas regionalidades por parte dos alunos da escola israelita e o não compartilhamento dessas por parte de Ana, não-judia. Bourdieu (2003, p. 124) enfatiza:

sabe-se que os indivíduos e os grupos investem nas lutas de classificação todo o seu ser social, tudo o que define a ideia que eles têm deles próprios, todo o impensado pelo qual eles se constituem como 'nós' por oposição a 'eles', aos 'outros' e ao qual estão ligados por uma adesão quase corporal. É isto que explica a força mobilizadora excepcional de tudo o que toca à identidade.

Identificar-se é estabelecer limites simbólicos ${ }^{4}$, através de sinais diacríticos, com a finalidade de distinguir-se do outro, pela expressão, num processo dialético de identidade/alteridade. Assim, não se pode falar em identidade, sem falar em diferença, pois são processos inseparáveis que se criam cultural, social e simbolicamente (SILVA, 2000). De acordo com Kehl (1996), quando falamos em diferença estamos falando de produção de identidades. Identidade e diferença também não são fenômenos isolados; pelo contrário, convivem em campos de poder e de hierarquia: "a identidade e a diferença se traduzem, assim, em declarações sobre quem pertence e sobre quem não pertence, sobre quem está incluído e quem está excluído. Afirmar a identidade significa demarcar fronteiras, significa fazer distinções entre o que fica dentro e o que fica fora" (SILVA, 2000, p. 82). Clara e a maioria dos seus colegas da escola israelita demarcam as suas fronteiras simbólicas e identitárias ao julgar Ana e sua família como não sendo "dos nossos" (MOSCOVICH, 2004, p. 25).

Outro aspecto que diferencia as culturas e que, portanto, funciona como mecanismo de identificação é a língua. Barcia (2004) defende que a língua é um dos principais aspectos que constituem uma região cultural. No caso judaico, o uso do hebraico foi mantido por diversas comunidades judaicas, após as diásporas, como forma de manutenção de nacionalidade. Segundo Hobsbawn (1990, p. 70), "as línguas nacionais são sempre, construtos semiartificiais e, às vezes, virtualmente inventados, como o moderno hebreu." Em função de a comunidade judaica babilônica ter se dispersado, os judeus estabeleceram-se, principalmente, na Europa, divididos em dois grupos: os sefaradins e os ashkenazims. Os ashkenazims eram originários

\footnotetext{
${ }^{4}$ Para Barth (1998), fronteiras simbólicas.
} 
dos judeus que se estabeleceram na Alemanha, em Aschkenaz, e falantes de iídiche, uma mistura de hebraico e alemão. (SILVA; SILVA, 2010). No Rio Grande do Sul, algumas das primeiras gerações de imigrantes judeus possuíam o iídiche como idioma do cotidiano, sendo seu uso também forte nas manifestações teatrais em Porto Alegre. Porém, nas escolas israelitas e escolas mistas, como a escola de Clara, a língua portuguesa e o hebraico eram os idiomas ensinados. (GUTDREIND, 2004). De acordo com Hobsbawn (1990), o nacionalismo judeu foi inventado, no final no século XIX (assim como as demais comunidades imaginadas), e a língua oficial dos judeus, o hebraico moderno falado, também foi inventada. Essa invenção ocorreu em função de uma questão ideológica e de poder nacionalista (não por motivos de comunicação ou de cultura), e foi um caso de nacionalismo linguístico bem sucedido, mesmo sendo uma língua que ainda ninguém falava, com uma pronúncia diferente daquele hebraico antigo e tradicional, usado nas sinagogas. O iídiche, embora falado, à época, por mais de $95 \%$ dos judeus ashkenazims e sendo considerada uma língua culta e de rica literatura, não foi definido como língua oficial. Em 1919, as pessoas que realmente falavam o hebraico moderno eram, aproximadamente, 20 mil; porém, mesmo tratando-se de um número relativamente baixo de falantes, a Inglaterra considerou o hebraico uma das línguas oficiais da Palestina (HOBSBAWN, 1990). Dessa forma, falar o hebraico moderno era uma maneira de veicular e perpetuar o nacionalismo judeu.

Clara, durante a narrativa de sua história, usa termos em hebraico, seguidos de suas definições, para explicar os costumes da sua cultura. Ao citar termos em hebraico e passagens da Torá, quando narra os costumes judaicos em relação à morte, Clara ressignifica a memória coletiva judaica através da língua:

acompanhar os trabalhos funerários é também considerada uma obrigação religiosa [...]. Originalmente, as sete pausas da procissão do enterro no caminho da sepultura correspondiam às sete formas gramaticais da palavra hevel (morte, transitoriedade), os sete dias da criação e os sete estágios da vida. Durante as pausas, rezas são lidas, a exemplo dos Salmos 16 ou $91 .^{5}$ (MOSCOVICH, 2004, p. 71-72).

Mesmo diante da ausência de um território em comum, a preservação da identidade judaica ocorreu, em grande parte, graças à utilização da Torá como referência, além da

\footnotetext{
${ }^{5}$ Os verbos, em hebraico bíblico, como hevel (morte/morrer), possuem sete conjugações: a primeira conjugação é considerada o tronco básico, as demais, são os troncos derivados. (KELLEY, 1998). Hevel é, também, em hebraico, a versão para o nome Abel, filho de Adão e Eva. Em virtude do fato de ter sido morto por seu irmão, Caim, a palavra hevel, embora geralmente traduzida por vaidade, também significa morte, pois Abel foi o primeiro ser humano a morrer e a oferecer sua vida a Deus, de acordo com o livro do Eclesiastes da Bíblia Judaica. Abel, ou Hevel, representa, assim, algo maior que a morte, pois, em função de sua mortalidade, ocorreu seu contato com Deus. O significado da palavra hevel assume, a partir desse contato, o sentido de transitoriedade, transcendência. (DOR-SHAV, 2008).
} 
realização de outros costumes e tradições, como as celebrações e festividades, os hábitos e restrições alimentares, a prática da circuncisão, a matrilinearidade (MENTLIK, 2005).

Além do uso do hebraico no reduto doméstico, a família da Clara pratica muitos dos costumes judaicos. Em função da morte do pai, praticam-se, durante o funeral, algumas tradições. Após o banho ritual do falecido, juntamente com o rabino, permanecem apenas os familiares para a cerimônia do corte das roupas dos enlutados, como a maior expressão de dor diante da perda ${ }^{6}$. Clara narra a execução do costume:

as mãos do rabino, poderosas, estavam prontas para o ofício do luto, todos sabiam e esperavam. E, num gesto, sem ninguém se dar conta de onde havia surgido, já uma lâmina de barbear, meio fosca de uso, resplandecia entre seus dedos. Os olhares se concentraram, magnetizados pelo metal. $\mathrm{O}$ homem deu um passo em direção à minha mãe e, cumprindo o esperado, deu-lhe um longo talho na gola. Ela olhou o rabino, a expressão dura e intransitiva. Depois, seguindo-se o pesadelo, os meninos, cada qual a seu tempo, tiveram as vestes rasgadas, os olhos inundados do pranto legítimo e pontual. Não havendo volta atrás, ofereci a blusa à imolação, a lâmina cega vencendo a resistência do tecido aos trancos, as fibras separando-se, rilhando nos dentes. O terno negro do tio foi também lacerado. Outro, mais um dos pactos ancestrais, se desenrolava ali, à distância de centímetros, a mesma perda que assolou Abraão, o mesmo gesto de esfarrapar a roupa em desespero, a mesma imponência diante do desígnio. (MOSCOVICH, 2004, p. 76-77).

Após a morte de um familiar, conforme o judaísmo, os espelhos da casa devem ser cobertos: "essa era a hora em que deveríamos cobrir os espelhos da casa, ocultando a falta do rosto que ali não mais estaria." (MOSCOVICH, 2004, p. 81). Outro costume mantido pela família, causador das terríveis dores de cabeça que perturbam Clara após a morte do pai, é a realização do levirato. De acordo com esse costume, os irmãos do marido falecido, que estiverem solteiros, têm o dever de cuidar da viúva e de seus filhos, a fim de que se possa dar continuidade à família e aos negócios (LÉVI-STRAUSS, 1986). A mãe de Clara casa-se com o tio, que passa a assumir o papel de chefe da família, a contragosto da narradora.

Entretanto, alguns dos costumes judaicos não são reproduzidos, afinal, em função da nova formação cultural, novas regionalidades surgem, e algumas nacionalidades se dispersam, "a história move-se vertiginosamente, traz mudanças, aproxima, separa, cria outras condições de vida" (GUTFREIND, 2004, p. 147). É o caso de algumas tradições, já não mais praticadas nesse novo contexto cultural: "nas áreas rurais europeias, ainda se mantém a antiga tradição segundo a qual, na saída do enterro, as pessoas devem jogar, sobre os ombros, punhados de grama e terra, como um símbolo de transitoriedade." (MOSCOVICH, 2004, p. 74). A família de Clara deixa o enterro do pai sem realizar essa cerimônia.

\footnotetext{
${ }^{6}$ Informações obtidas da página <www.chabad.org.br>. Acesso em: 31 ago. 2014.
} 
As práticas de regionalidade não existem independentemente; pelo contrário, são realizadas por sujeitos. Clara pertence a uma região cultural que possui tradições bastante rígidas e acaba agindo de acordo com as regionalidades determinadas por essa região. De acordo com Barth (1998, p. 199), "o indivíduo deverá evitar, no conjunto do sistema social, os estatutos e as situações que implicam um comportamento em desacordo com suas orientações valorativas, já que um comportamento desse tipo de sua parte será sancionado de maneira negativa." Clara, assim, age, em muitos momentos, de acordo com o que se espera dela enquanto membro do grupo cultural judaico. Casa-se, conforme desejo do pai, com um judeu, pois, dessa forma, um homem poderia dar continuidade aos negócios. Casando-se com um descendente de rabino, Clara poderia constituir uma família e garantir a transmissão das tradições judaicas aos seus futuros filhos, como fizeram, anteriormente, o pai e a mãe, os avós e antecessores. O trecho a seguir revela essa típica constituição familiar judaica, em que ao homem se destinam os negócios e à mulher se destina o espaço privado:

cumpre dizer que dois fatos primordiais regem a vida judaica: o guisheft - o negócio, geralmente uma pequena casa comercial, que, ao longo dos séculos, tem garantido a subsistência familiar -, e os filhos, alegria na juventude e amparo na velhice. Dessa maneira, o primeiro impulso de um judeu é o de lutar pela posse de seu nariz: ou bem estuda, torna-se um profissional liberal, abre um consultório ou escritório - e dá uma passada nos finais de tarde no negócio dos pais para saber como foi o movimento do dia -, ou bem herda o guisheft que pertence, e sempre pertencerá, à família. Meu pai, cuja herança ficara bem para trás, em terras da Bessarábia, não teve outra alternativa senão a de começar ele mesmo um legado inverso, aquele que ajudaria a sustentar meus avós, o folgazão do meu tio, e os filhos que ele, meu pai, tanto queria ter. [...] Exitosa a empreitada do filho mais velho, meu avô abandonou a mala de couro gordurenta e os lamentáveis panos coloridos, gastando as tardes a praticar em iídiche com outros velhos no Bom Fim; minha avó, na ampla cozinha em que vivi parte da infância e que dava de frente para a Fernandes Vieira, preparava os caldos e knishes para a janta da família. (MOSCOVICH, 2004, p. 103-104).

Conforme Green (1995, p. 263), "o Judaísmo atribui um lugar claramente diferenciado a homens e mulheres. Para uns o público, para outras o privado. Para eles serviços religiosos, para elas só preparar a comida do Sabat." ${ }^{7} \mathrm{O}$ preparo das refeições é bastante valorizado na cultura judaica, tido como algo sagrado e atribuído às mulheres ${ }^{8}$. Clara, nas visitas que faz à família - não-judia - de sua amiga Ana, surpreende-se com o fato de que o pai de sua amiga cozinha. No entendimento da jovem judia, somente as mulheres cozinhavam: "Aninha cozinhava, a mãe de Aninha cozinhava e, mais alarmante, o pai de Aninha cozinhava. [...] Para nosso entendimento, era excepcional que todos na casa se dessem bem com as coisas do fogão." (MOSCOVICH, 2004, p. 25).

\footnotetext{
${ }^{7}$ O Sabat, ou Shabat, em hebraico, significa "descanso". É o sétimo dia, em que Deus descansou, após a criação terrestre. Na religião judaica, o Shabat inicia na sexta-feira e termina na noite de sábado.

${ }^{8}$ Por que sou gorda, mamãe? (2006), de Cíntia Moscovich, traz a temática da importância da comida na cultura judaica.
} 
A gastronomia, segundo Arendt (2012), também se configura como uma prática de regionalidade e de afirmação de identidade, pois distingue uma região de outros contextos culturais mais amplos. Para Topel (2003), as leis alimentares judaicas fazem com que os judeus tornem públicas suas identidades religiosas e culturais, procurando distinguir-se de outros grupos culturais:

as comidas étnicas oferecem um rico jogo de metáforas através das quais se expressam as relações dos sujeitos com um grupo particular. Esse processo fica mais evidente em comunidades novas, pequenas, minoritárias, ou nas quais há um significativo número de novos adeptos, a exemplo das comunidades religiosas que perseguem, de uma forma ou de outra, a incorporação de novos membros. (TOPEL, 2003, p. 204)

A culinária praticada pelas famílias da região cultural judaica de Porto Alegre é um dos principais elementos que distinguem essa região das demais áreas da capital gaúcha. Novamente, aqui, tem-se a ressignificação de uma nacionalidade em regionalidade, visto que a gastronomia judaica, em contato com um novo contexto de inserção, sofre algumas alterações, sempre, no entanto, na busca contínua da manutenção da tradição judaica, baseada nas leis dietéticas judaicas ${ }^{9}$. Clara menciona o consumo do gefiltefish (MOSCOVICH, 2004, p. 121), "carne de peixe (geralmente carpa) moída e misturada com ovos, farinha, cebola, cenouras e temperos diversos" (SCLIAR, 2007, p. 42).

Permanência das tradições culinárias, uso da língua, culto de uma memória coletiva em comum, entre outros aspectos, fazem da comunidade regional do Bom Fim, representada na obra Duas iguais, uma comunidade que ressignificou sua identidade judaica sem abandonar os principais elementos da cultura de origem. De acordo com Mentlik (2005, p. 64), os judeus "foram bem-sucedidos em transportar consigo suas tradições e valores culturais, transplantando-os ao novo país e impondo, assim, com um ritmo mais lento à sua própria aculturação, um respeito maior à sua integridade como indivíduos e uma valorização da herança cultural de que eram portadores". Percebe-se que, na obra analisada, a comunidade regional judaica literariamente representada confirma a existência de inter-relações entre memória, territorialidade e identidade cultural nacional e regional. A família de Clara representa uma comunidade que, mesmo diante de um território totalmente diferente de seu lugar de origem, foi capaz de manter grande parte das características identitárias intacta,

\footnotetext{
${ }^{9}$ A dieta judaica é conhecida como dieta kasher, uma dieta adequada que deve ser seguida. De acordo com Topel (2003), essa dieta deve seguir algumas normas em relação à proibição de certos alimentos e práticas (como o consumo de carne suína) e em relação ao preparo dos alimentos e uso de utensílios (não ingerir carne e leite na mesma refeição, nem usar os mesmos utensílios domésticos para o consumo de ambos). É importante ressaltar que nem todos os judeus adotam uma dieta kasher, o que tem funcionado como aspecto distintivo entre as vertentes do judaísmo. Além disso, muitas vezes, adotar ou não essa dieta implica adotar outros costumes, como restringir o grupo de amigos apenas a judeus ou realizar essa dieta apenas em casa.
} 
promovendo a permanência da cultura judaica. Mesmo diante de históricas perseguições, diásporas e genocídios, os judeus mantiveram viva sua memória coletiva e, em função disso, são, ainda hoje, capazes de reivindicar sua identidade cultural, elemento fundamental para sua constituição enquanto sujeitos.

\section{Referências}

ANDERSON, Benedict R. Comunidades imaginadas: reflexões sobre a origem e a difusão do nacionalismo. Trad. de Denise Bottman. São Paulo: Companhia das Letras, 2008.

ARENDT, João Claudio. Contribuições alemãs para o estudo das literaturas regionais. Pandaemonium Germanicum, n. 17, São Paulo, 2011. p. 217-238. Disponível em: <http://www.scielo.br/scielo.php?script=sci_arttext\&pid=S198288372011000100012\&l $\mathrm{ng}=\mathrm{pt} \& \mathrm{nrm}=\mathrm{iso} \& \mathrm{t} \operatorname{lng}=\mathrm{pt}>$. Acesso em: 28 jan. 2014.

. Do outro lado do muro: regionalidades e regiões culturais. RUA [online]. 2012, n. 18, v. $2, \quad$ p. 82-99. Disponível em: < http://www.labeurb.unicamp.br/rua/pages/home/capaArtigo.rua?id=136>. Acesso em: 30 jan. 2014.

BARCIA, Pedro Luis. Hacia um concepto de la literatura regional. In: CASTELLINO, Marta Elena; RIVERO, Gloria Videla de. (Org.). Literatura de las regiones argentinas. Mendoza: Universidad Nacional Del Cuyo, 2004, p. 25-45.

BARTH, Fredrik. Grupos étnicos e suas fronteiras. In: POUTIGNAT, Philippe; STREIFFFENART, Jocelyne. Teorias da etnicidade. São Paulo: Ed. da Unesp, 1998. p. 187-228.

BERUMEN, Humberto Félix. La frontera en el centro: ensayos de literatura. Mexicali, Baja California: Universidad Autónoma, 2005.

BOURDIEU, Pierre. A identidade e a representação: elementos para uma reflexão crítica sobre a ideia de região. In: O poder simbólico. 6. ed. Trad. de Fernando Tomaz. Rio de Janeiro: Bertrand Brasil, 2003. p. 107-132.

BURKE, Peter. Hibridismo cultural. São Leopoldo, RS: Unisinos, 2003.

CANDAU, Joël. Memória e identidade. Trad. de Maria Leticia Ferreira. São Paulo: Contexto, 2012.

CARNEIRO, Maria Luiza Tucci. O anti-semitismo nas Américas: memória e história. São Paulo: EDUSP, 2007.

CYTRYNOWICZ, Roney. O silêncio do sobrevivente: diálogo e rupturas entre memória e história do Holocausto. In: SELIGMANN-SILVA, Márcio. (Org.). História, memória, literatura: o testemunho na era das catástrofes. Campinas, SP: Editora da Unicamp, 2003. p. 123-138.

DIAS, Selene de Souza. As representações do corpo feminino na literatura e nas artes visuais judaicas da América Latina. Arizona: University of Arizona, 2012. 233 p. Disponível em: <http://arizona.openrepository.com/arizona/handle/10150/247256>. Acesso em: 30 jan. 2014.

DOR-SHAV, Ethan. Ecclesiastes, fleeting and timeless: part I. Jewish Bible Quarterly, Israel, v. 36, n. 4, out./dez. 2008, p. 211-222. Disponível em: 
<http://jbq.jewishbible.org/assets/Uploads/364/364_dorshav1.pdf>. Acesso em: 28 jan. 2014.

FREYRE, Gilberto. Interpretação do Brasil: aspectos da formação social brasileira como processo de amalgamento de raças e culturas. São Paulo: Companhia das Letras, 2001.

GREEN, Nancy L. A formação da mulher judia. In: DUBY, Georges; PERROT, Michelle. (Org.). História das mulheres no ocidente. Portugal: Afrontamento, 1993-1995. v. 4. p. 256-275.

GUTFREIND, Ieda. A imigração judaica no Rio Grande do Sul: da memória para a história. São Leopoldo, RS: UNISINOS, 2004.

HALL, Stuart. A identidade cultural na pós-modernidade. Trad. de Tomaz Tadeu da Silva e Guaracira Lopes Louro. 10. ed. Rio de Janeiro: DP\&A, 2005.

HOBSBAWN, Eric J. Nações e nacionalismo desde 1780: programa, mito e realidade. Trad. de Maria Celia Paoli e Anna Maria Quirino. Rio de Janeiro: Paz e Terra, 1990.

KEHL, Maria Rita. Mínima diferença: masculino e feminino na cultura. Rio de Janeiro: Imago, 1996.

KELLEY, Page. Hebraico bíblico: uma gramática introdutória. 7. ed. Trad. de Marie Ann Wangen Krahn. São Leopoldo: Editora Sinodal, 1998.

LEVI-STRAUSS, Claude. A família. In: ___ . O olhar distanciado. Trad. de Carmen de Carvalho. Lisboa: Edições 70, 1986. Disponível em: $<$ http://pt.scribd.com/doc/6303659/O-Olhar-Distanciado-Claude-LeviStrauss->. Acesso em: 29 jan. 2014.

LOWENTHAL, David. Como conhecemos o passado. Projeto história. São Paulo, n. 17, nov. 1998, p. 63-201. Disponível em: <http://www.pucsp.br/projetohistoria/downloads/revista/PHistoria17.pdf>. Acesso em: 30 jan. 2014.

MASSEY, Doreen B. Pelo espaço: uma nova política da espacialidade. Tradução de Hilda Pareto Macial e Rogério Haesbaert. Rio de Janeiro: Bertrand Brasil, 2008.

MENTLIK, Célia Szniter. As migrações e seus reflexos na cultura: alguns fatos e perspectivas sobre a imigração e a história da presença judaica no Brasil. Métis: história e cultura. Caxias do Sul, v. 4, n. 8, p. 61-76, jul./dez. 2005. Disponível em: <http://www.ucs.br/etc/revistas/index.php/metis/article/viewArticle/1182>. Acesso em: 28 jan. 2014.

MOSCOVICH, Cíntia. Duas iguais. Rio de Janeiro: Record, 2004.

OLIVEIRA, Roberto Cardoso de. Caminhos de identidade: ensaios sobre etnicidade e multiculturalismo. São Paulo: Editora Unesp; Brasília: Paralelo 15, 2006.

POLLAK, Michael. Memória e identidade social. Estudos históricos, Rio de Janeiro, v. 5, n. 10, p. 1-15, 1992. Disponível em: <http://reviravoltadesign.com/080929_raiaviva/info/wp-gz/wpcontent/uploads/2006/12/memoria_e_identidade_social.pdf>. Acesso em: 30 jan. 2014.

POZENATO, José Clemente. Processos culturais: reflexões sobre a dinâmica cultural. Caxias do Sul: Educs, 2003.

SANTOS, Rafael José dos. Relatos de regionalidade: tessituras da cultura. Antares: letras e humanidades. Caxias do Sul, n. 2, p. 5-26, 2009. Disponível em: 
<http://www.ucs.br/etc/revistas/index.php/antares/article/viewArticle/399>. Acesso em: 30 jan. 2014.

SANTOS, Maria Medianeira dos; SOARES, Paulo Roberto Rodrigues. Reflexões sobre identidade judaica e gênero no seu processo de (re)territorialização no Rio Grande do Sul. Revista latinoamericana de geografia e gênero, Ponta Grossa, v. 3, n. 2, p. 106115, ago./dez. 2012, p. 106-115. Disponível em: <http://www.revistas2.uepg.br/index.php/rlagg/article/view/3328/pdf_37>. Acesso em: 4 set. 2014.

SARLO, Beatriz. Tempo passado: cultura da memória e guinada subjetiva. Trad. de Rosa Freire d'Aguiar. São Paulo: Companhia das Letras; Belo Horizonte: UFMG, 2007.

SCLIAR, Moacyr. Abc do mundo judaico. São Paulo: Edições SM, 2007.

SELIGMANN-SILVA, Márcio. Apresentação da questão: a literatura do trauma. In: (Org.). História, memória, literatura: o testemunho na era das catástrofes. Campinas, SP: Editora da Unicamp, 2003. p. 45-58.

SELTZER, Robert M. Povo judeu, pensamento judaico: a experiência judaica na história. Rio de Janeiro: A. Koogan, 1990. 2 v.

SENNET, Richard. Carne e pedra. Trad. de Marcos Aarão Reis. Rio de Janeiro: Bestbolso, 2008.

SILVA, Tomaz Tadeu da. A produção social da identidade e da diferença. In: SILVA, Tomaz Tadeu da. (Org.). Identidade e diferença: a perspectiva dos estudos culturais. Petrópolis: Vozes, 2000. p. 73-102.

SILVA, Kalina Vanderlei; SILVA, Maciel Henrique. Dicionário de conceitos históricos. 3. ed. São Paulo: Contexto, 2010.

THIESSE, Anne-Marie. Ficções criadoras: as identidades nacionais. Revista Anos 90. Porto Alegre, n. 15, 2001/2002, p. 7-23. Disponível em: <http://seer.ufrgs.br/anos90/article/view/6609/3932>. Acesso em: 30 jan. 2014.

TOPEL, Marta F. As leis dietéticas judaicas: um prato cheio para a antropologia. Horizontes antropológicos, Porto Alegre, a. 9, n. 19, jul 2003, p. 203-222. Disponível em: <http://www.scielo.br/pdf/ha/v9n19/v9n19a08.pdf>. Acesso em: 29 jan. 2014.

WALDMAN, Berta. A memória vicária em Ver: amor, de David Grossman. WebMosaica, Revista do Instituto Cultural Judaico Marc Chagall, v.1 n.2, jul-dez 2009, p. 73-81. Disponível em: <http://www.seer.ufrgs.br/webmosaica/article/view/1198>. Acesso em: 4 set. 2014. 